\title{
Assessment of immunogenicity of romiplostim in clinical studies with ITP subjects
}

\author{
Vibha Jawa • Martha Hokom • Zheng Hu • \\ Naglaa El-Abaadi • Yao Zhuang • Dietmar Berger • \\ Shalini Gupta $\cdot$ Steven J. Swanson • Narendra Chirmule
}

Received: 17 March 2009/Accepted: 20 January 2010/Published online: 13 February 2010

(C) The Author(s) 2010. This article is published with open access at Springerlink.com

\begin{abstract}
Romiplostim is an Fc-peptide fusion protein that activates intracellular transcriptional pathways via the thrombopoietin (TPO) receptor leading to increased platelet production. Romiplostim has been engineered to have no amino acid sequence homology to endogenous TPO. Recombinant protein therapeutics can be at a risk of development of an antibody response that can impact efficacy and safety. Hence, a strategy to detect potential antibody formation to the drug and to related endogenous molecules can be useful. The immunogenicity assessment strategy involved both the detection and characterization of binding and neutralizing antibodies. The method for detection was based on a surface plasmon resonance biosensor platform using the Biacore 3000. Samples that tested positive for binding antibodies in the Biacore immunoassay were then tested in a neutralization assay. Serum samples from 225 subjects with immune thrombocytopenic purpura (ITP) dosed with romiplostim and 45 ITP subjects dosed with placebo were tested for romiplostim and TPO antibodies. Prior to romiplostim treatment, 17 subjects (7\%) tested romiplostim antibody positive and 12 subjects (5\%) tested TPO antibody positive for pre-existing
\end{abstract}

\footnotetext{
Statement of prior presentation

Presented in abstract form at the 49th Annual Meeting of the American Society of Hematology, San Francisco, CA, USA, December 8, 2008.

V. Jawa $(\bowtie) \cdot$ M. Hokom $\cdot$ Z. Hu $\cdot$ N. El-Abaadi $\cdot$ Y. Zhuang $\cdot$

S. Gupta $\cdot$ S. J. Swanson $\cdot$ N. Chirmule

Clinical Immunology, Medical Sciences, Amgen Inc,

One Amgen Center Drive, 30E-3-B,

Thousand Oaks, CA 91320, USA

e-mail: vibha.jawa@amgen.com

D. Berger

Global Development, Amgen Inc,

One Amgen Center Drive,

Thousand Oaks, CA 91320, USA
}

binding antibodies. After romiplostim exposure, $11 \%$ of the subjects exhibited binding antibodies against romiplostim and $5 \%$ of the subjects with ITP showed binding antibodies against TPO. The antibodies against romiplostim did not cross-react with TPO and vice versa. No cases of anti-TPO neutralizing antibodies were detected in romiplostim-treated subjects. The incidence of anti-romiplostim neutralizing antibodies to romiplostim was $0.4 \%$ (one subject); this subject tested negative at the time of follow-up 4 months later. No impact on platelet profiles were apparent in subjects that had antibodies to romiplostim to date. In summary, administration of romiplostim in ITP subjects resulted in the development of a binding antibody response against romiplostim and TPO ligand. One subject developed a neutralizing antibody response to romiplostim that impacted the platelet counts of this subject. No neutralizing antibodies to endogenous TPO were observed.

Keywords Immune thrombocytopenic purpura (ITP) . Romiplostim $\cdot$ Immunogenicity $\cdot$ TPO $\cdot$ Platelet

\section{Introduction}

Romiplostim (formerly known as AMG 531) is a novel thrombopoiesis-stimulating protein (peptibody) that binds to and activates the human thrombopoietin (TPO) receptor leading to an increase in platelet production. Romiplostim has no amino acid sequence homology to endogenous TPO $[1,2]$. Chronic immune thrombocytopenic purpura (ITP) is an autoimmune disorder usually characterized by platelet destruction caused by anti-platelet antibodies [3-5]. Subjects with this disorder were administered romiplostim as a potential therapeutic option for increasing platelet counts in a series of clinical trials.

As with all therapeutic proteins, there is a potential for subjects to develop antibodies against the therapeutic. 
Cross-reactive antibodies to PEG-rHuMGDF have led to thrombocytopenia following administration of multiple doses of pegylated recombinant human MGDF (PEGrHuMGDF) to healthy volunteers and cancer subjects [68]. Hence, when administered romiplostim, subjects might be at a risk to develop antibodies to romiplostim or crossreactive antibodies to TPO. Such cross-reactive antibodies might be low affinity conformational antibodies that can still neutralize the endogenous thrombopoietin. To address this potential concern of immunogenicity, validated assays that can measure low and high affinity binding and neutralizing antibodies to romiplostim or TPO were developed. Utilizing the recommended immunogenicity assessment strategy [9-11], binding antibodies to romiplostim and/or TPO were monitored throughout the clinical drug development of romiplostim. In addition, samples identified positive in these assays were further characterized by determining their subclasses and affinity $[12,13]$.

The aim of the study was to assess the presence of these antibodies to romiplostim and TPO and discuss their possible impact on platelet levels. The study also discussed the impact of ITP and its related autoimmune disease status on apparent induction of an immune response prior to exposure to romiplostim.

\section{Clinical studies and methods}

Immunogenicity to romiplostim was evaluated in two clinical studies (Phase 1) with healthy subjects $(n=56)$ and ten clinical studies with ITP subjects $(n=235$; diagnosed per American Society of Hematology guidelines). Data presented in this paper is from 235 subjects (225 dosed with romiplostim and ten "placebo-only" dosed) who were evaluated for the presence of antibodies to romiplostim and/or TPO. A total of 45 subjects were initially dosed with placebo (in the placebo-controlled arm of one Phase 2 and two Phase 3 studies), however, 35 of these subjects were subsequently dosed with romiplostim in the ongoing Phase 3 open-label long-term extension study. Therefore, only ten "placebo-only" dosed subjects remained at the time of final analysis. The antibodies were assessed prior to dosing ("pre-existing") and after dosing ("post-exposure") with romiplostim. The strategy for immunogenicity assessment is outlined in Fig. 1.

Biacore immunoassay for binding antibody detection

A surface plasmon resonance (SPR)-based immunoassay was used for evaluating binding antibodies to romiplostim, thrombopoietin mimetic peptide (TMP), and TPO [9, 11, 14]. The multiple flow cell SPR-based assays enabled epitope mapping by assessing the immune reactivity to either the peptide component TMP or Fc portion of romiplostim in the same sample [15]. Briefly, romiplostim, TMP, and TPO were covalently immobilized through free amines to a carboxy-methylated sensor chip on a Biacore 3000 instrument. Serum samples were diluted to $50 \%$ in TBS-EP sample diluent. Ten microliters of diluted serum samples and assay controls were individually injected sequentially across the romiplostim, TMP, and TPO surface at a rate of $5 \mu \mathrm{L} / \mathrm{min}$. The samples were confirmed to be antibodies with a secondary goat anti-human $\mathrm{F}(\mathrm{ab})_{2}$. The surfaces were regenerated using guanidine- $\mathrm{HCl}$ plus Tween 20. The threshold of the assay was calculated as the upper bound of a one-sided $95 \%$ above a background response provided by analysis of baselines from 141 subjects with ITP. Any sample testing at or above threshold was considered positive, pending additional specificity testing. Based on titration of the anti-TPO and anti-romiplostim positive control antibody, the limit of anti-TPO and antiromiplostim antibody detection was 200 and $400 \mathrm{ng} / \mathrm{mL}$, respectively. The specificity of binding to TPO and romiplostim observed in serum samples was confirmed by competition through the addition of excess of TPO or romiplostim to the serum sample before testing. A $50 \%$ or greater reduction in net resonance unit (RU) signal was required for a positive result for drug specificity. Only samples that tested above the assay threshold and demonstrated drug specificity were considered positive for antiTPO and/or anti-romiplostim/TMP antibodies.

\section{Biological assay for neutralizing antibody detection}

Once the samples were confirmed for binding antibodies, their neutralizing capability was assessed using a biological assay. The sensitive neutralizing bioassay utilizes a murine cell line 32Dclone23 transfected with the human thrombopoietin receptor gene $c-m p l$. This cell line was maintained in growth medium supplemented with mIL-3. The 32Dclone23 cells respond to romiplostim and TPO stimulation by proliferation. A pre-incubation of romiplostim with anti-romiplostim antibodies blocks the cell proliferation. Similarly, in the TPO assay, a pre-incubation of TPO with anti-MGDF antibodies blocks the TPO-induced proliferation. Cells were grown in absence of mIL-3 overnight. Growth factor-deprived cells were then incubated with romiplostim or TPO in $1 \%$ serum matrix overnight. The proliferation was measured by ${ }^{3} \mathrm{H}-$ thymidine uptake. Cut-points were established from 100 ITP subjects treated with $250 \mathrm{pg} / \mathrm{mL}$ romiplostim or $75 \mathrm{pg} / \mathrm{mL}$ of TPO, respectively. These concentrations of romiplostim and TPO, respectively, demonstrated a tenfold rise above background and were the most optimal in inducing the proliferation of cells in the presence of serum from ITP subjects [16].

Samples that tested below the assay cut-points were diluted and treated with protein $\mathrm{G}$ beads, as well as, Sepharose control 


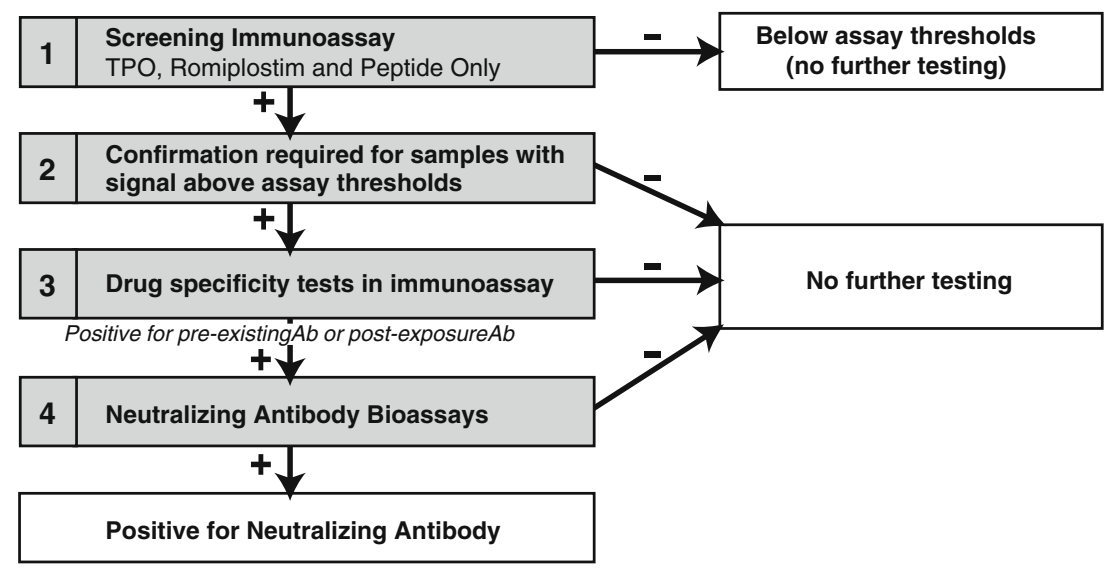

Fig. 1 Process for assessment of immunogenicity in the romiplostim clinical trial program. The strategy for immunogenicity assessment involved a screening step where the serum samples were assessed for their ability to bind to TPO, romiplostim, and peptide component of romiplostim. If the sample showed binding above the validated assay threshold, it was further confirmed in a specificity test. Based on the reactivity observed, excess of the relevant TPO or romiplostim was added to the reactive sample and assessed for neutralization of the reactive response. If the sample exhibited more than $50 \%$ depletion of signal in drug specificity analysis, the sample was then confirmed for its ability to neutralize romiplostim or TPO in a biological functional assay

For the neutralizing bioassays, a cut-point of $99 \%$ lower bound of least square mean was established for the ITP population. Total assay variance calculated by the analysis of variance method incorporated subject, day, and plate differences into the calculation of prediction limits.

\section{Results}

Overall immunogenicity of romiplostim in clinical studies in subjects with ITP

The number of subjects with binding and neutralizing antibodies to romiplostim and TPO in the clinical studies in subjects with ITP dosed with romiplostim and placebo, respectively, are shown in Tables 2 and 3. Clinical efficacy and safety evaluation in romiplostim-dosed subjects from five of the ten studies were published by the time of this analysis. Serum samples from 225 treated ITP subjects were tested for romiplostim and TPO antibodies prior to dosing with romiplostim. Seventeen subjects $(7 \%)$ tested romiplostim antibody positive and 12 subjects $(5 \%)$ tested TPO antibody positive for pre-existing binding antibodies.

Table 1 Summary of assay parameters for immunoassay and bioassay

\begin{tabular}{|c|c|c|c|c|}
\hline & \multicolumn{2}{|l|}{ Immunoassay } & \multicolumn{2}{|l|}{ Bioassay } \\
\hline & Romiplostim & ТPO & Romiplostim & TPO \\
\hline Assay sensitivity (ng/mL) & 400 & 200 & 400 & 200 \\
\hline Specificity/confirmatory & \multicolumn{2}{|c|}{ Depletion $>50 \%$ with $6.4 \mu \mathrm{g} / \mathrm{mL}$ of drug/ligand } & \multicolumn{2}{|c|}{ Depletion $>48 \%$ with protein $G$} \\
\hline Drug tolerance $(\mathrm{ng} / \mathrm{mL})$ & 10 & 10 & 25 & 6.3 \\
\hline
\end{tabular}


Following dosing with romiplostim, 25 out of 225 (11\%) subjects with ITP exhibited binding antibodies against romiplostim and 12 out of $225(5 \%)$ subjects with ITP showed binding antibodies against TPO. These subjects were not positive for antibodies to either romiplostim or TPO prior to exposure to the drug.

A total of 45 placebo subjects were evaluated for preexisting antibodies to romiplostim and TPO. Four of the 45 subjects $(9 \%)$ were positive for binding antibodies to romiplostim and six of $45(13 \%)$ subjects were positive for binding antibodies to TPO (Table 3).

A total of 56 healthy subjects were evaluated for binding and neutralizing antibodies to romiplostim and TPO in two Phase 1 clinical studies. Two of the 56 subjects (4\%) were positive for pre-existing antibodies to romiplostim and three of 56 subjects $(5 \%)$ were positive for pre-existing antibodies to TPO. Following exposure to romiplostim, one of the 56 subjects developed binding antibodies to romiplostim (2\%) and another one of 56 subjects developed binding antibodies to TPO (2\%; Fig. 2).

Neutralizing antibodies to romiplostim were detected in one subject out of $225(0.4 \%)$ subjects with ITP who were treated with romiplostim. This specific subject was first enrolled in a Phase 1-2 multicenter, open-label, unit dose-finding study of safety and efficacy of romiplostim in adult ITP subjects. The subject had a history of splenectomy and received romiplostim at unit doses of $100 \mu \mathrm{g}$ (equivalent to $1.06 \mu \mathrm{g} / \mathrm{kg}$ injection) on days 1 and 22 of this study. Their baseline platelet count at the time of initial enrollment was $31 \times 10^{9} / \mathrm{L}$. The subject completed the study per protocol, with platelet counts ranging from 25 to $110 \times 10^{9} / \mathrm{L}$. Blood samples obtained at baseline, on day 29 , and on day 78 end of study (EOS) were negative for both anti-romiplostim and anti-TPO neutralizing antibodies. The same subject was enrolled 21 months later in an ongoing long-term extension study. Baseline platelet counts at the time of enrollment were $24 \times 10^{9} / \mathrm{L}$. The subject was started on a romiplostim dose of $1 \mu \mathrm{g} / \mathrm{kg}$ and from week 2 until week 77, the dose was kept at 2 or $3 \mu \mathrm{g} / \mathrm{kg}$. The dose was tapered off to $1 \mu \mathrm{g} / \mathrm{kg}$ at week 78 based on the subject's request to discontinue the medication. At no time during weeks 2 to 79 were the subject's platelet counts below the baseline (week 1) value of $24 \times 10^{9} / \mathrm{L}$. The subject did not receive any ITP rescue medications during this time.

In the long-term extension study, antibodies were assessed at pre-dose and every 12 weeks during romiplostim treatment until EOS. The subject was negative for binding antibodies to romiplostim or TPO until week 12. The subject first developed binding antibodies to romiplostim at week 36 , but was negative for neutralizing antibodies. The platelet counts were in the range of 101 to $291 \times 10^{9} / \mathrm{L}$ from week 3 to week 40 . Blood samples obtained at week 60 and at week 66 were positive for anti-romiplostim binding antibodies, but were negative for anti-romiplostim neutralizing antibodies. The platelet counts from week 41 to week 55 and from week 56 to week 78 were in the range of 42 to $106 \times 10^{9} / \mathrm{L}$ and in the range of 43 to $87 \times 10^{9} / \mathrm{L}$, respectively. The blood sample obtained at week 79 (EOS) was positive for anti-romiplostim binding and neutralizing antibodies. At week 78 and at week $79 / \mathrm{EOS}$, the platelet counts were $76 \times 10^{9} / \mathrm{L}$ and $37 \times 10^{9} / \mathrm{L}$, respectively. A follow-up blood sample, obtained about 4 months after the week 79/EOS, tested positive for anti-romiplostim binding antibodies, but negative for antiromiplostim neutralizing antibodies. No binding or neutralizing antibodies to TPO were detected at any time-point. No platelet counts were assessed during follow-up at 4 months as the subject had discontinued the study (Fig. 3a).

One subject (from the Phase III study in non-splenectomized subjects) was positive for neutralizing antibodies to TPO at baseline (prior to romiplostim exposure); however, all of the post-dose sample time-points for the subject were negative for binding antibodies. This subject did not exhibit any clinical sequelae and there appears to be no impact on the platelet counts pre- or post-dosing with romiplostim (Fig. 3b).

Impact of immunogenicity on pharmacodynamics

The impact of binding antibodies on platelet counts was analyzed by longitudinal analyses (antibody time-point versus platelet counts) of all subjects in the studies [17-19]. The median platelet count profiles in the antibody positive subjects were very similar to the subjects that did not demonstrate post-exposure binding antibodies. Analyses of all the subjects with binding antibodies to romiplostim or TPO did not appear to have any impact on platelet profiles and the median platelet counts were maintained at $\geq 50 \times 10^{9} / \mathrm{L}$ for all romiplostimtreated subjects (data not shown).

\section{Cross-reactive antibodies to TPO}

Both the romiplostim- and placebo-dosed groups of ITP subjects exhibited anti-TPO binding antibodies (Tables 2 and 3). Anti-TPO binding antibodies were also observed in a small proportion of healthy subjects (Fig. 2). All subjects that demonstrated binding antibodies to romiplostim following dosing with romiplostim were tested for crossreactivity to TPO, and all the subjects with TPO positive samples were tested for cross-reactivity to romiplostim. No cross-reactivity was observed.

\section{Discussion}

We have assessed the immunogenicity of romiplostim, an efficacious therapeutic protein approved for the treatment of chronic ITP $[17,20]$. The ability to detect low affinity immune responses allows for a better understanding of the 


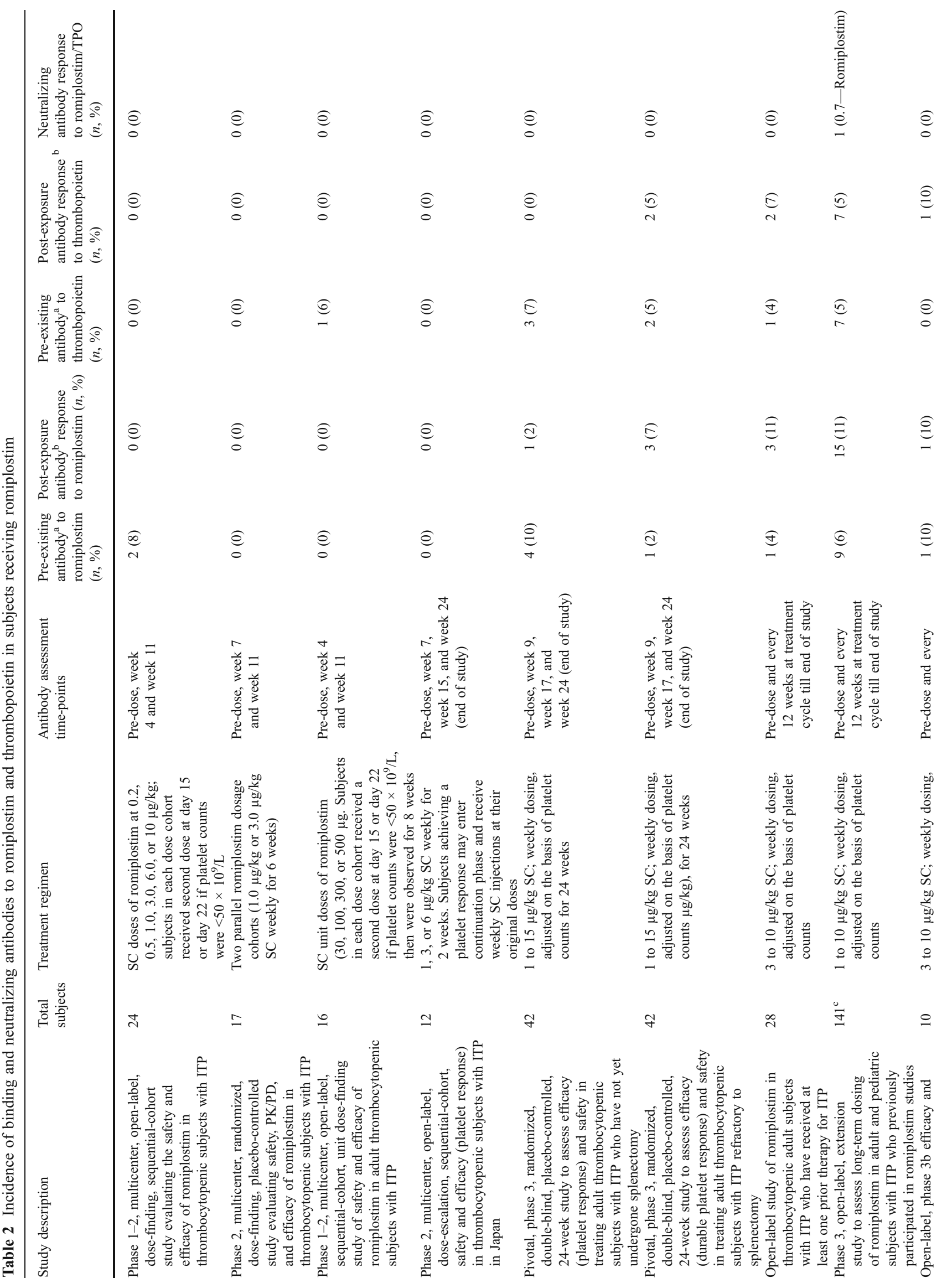




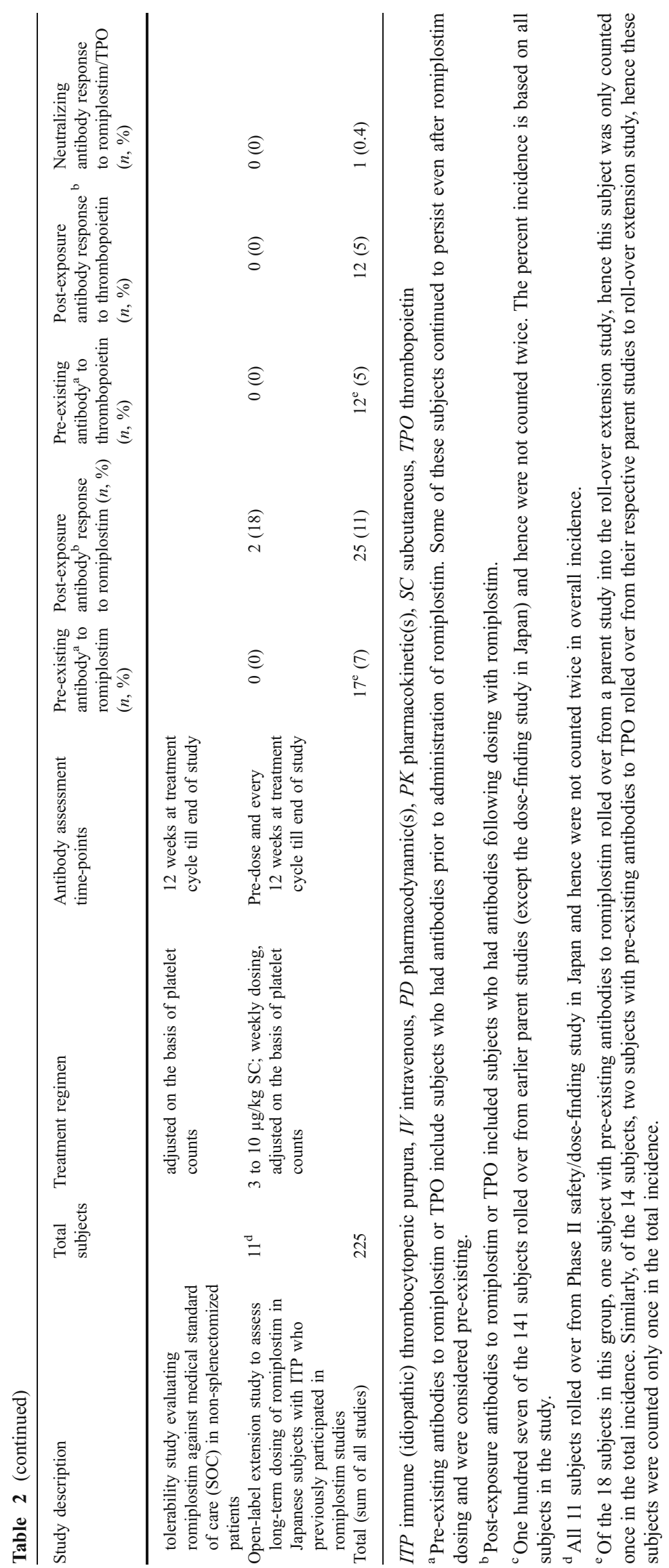




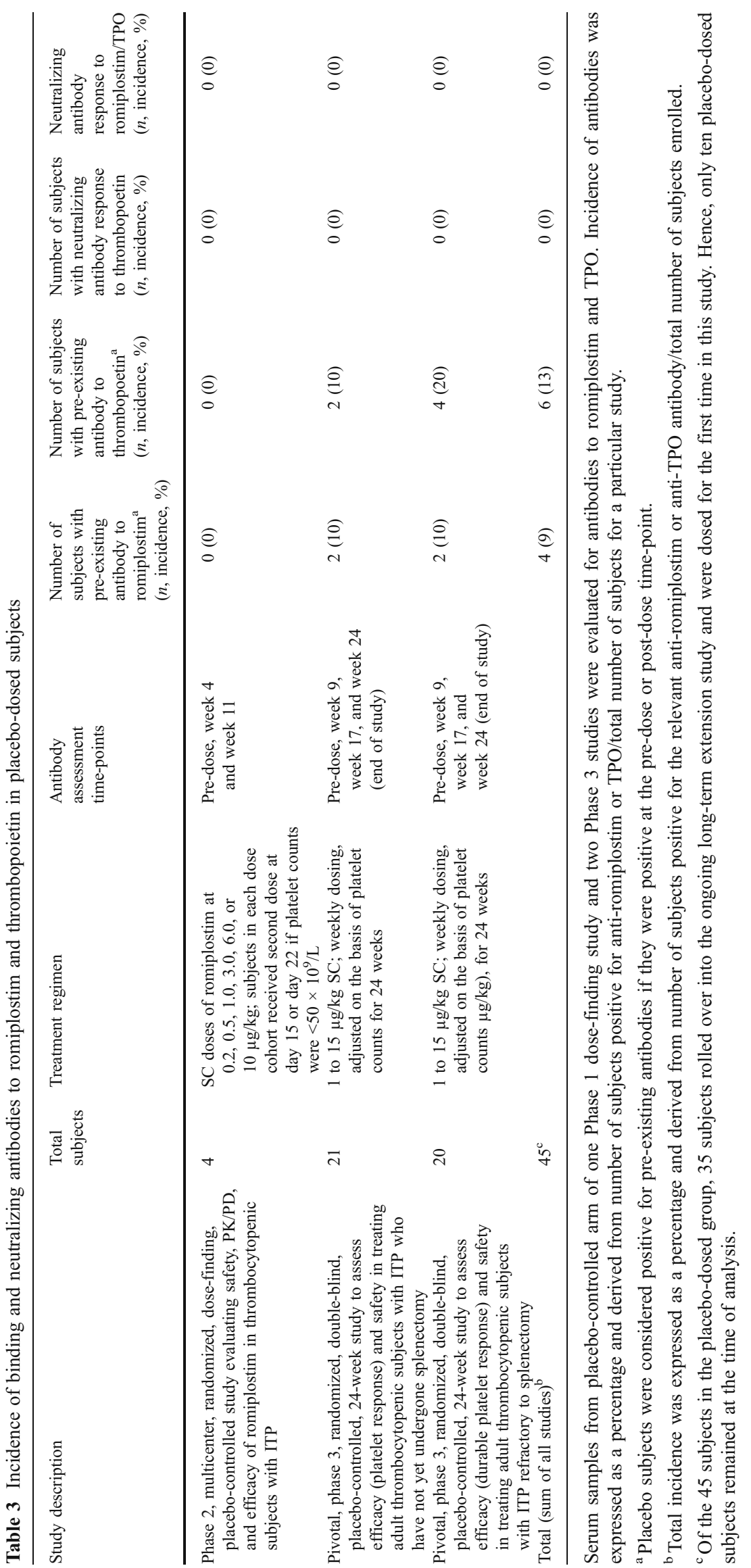




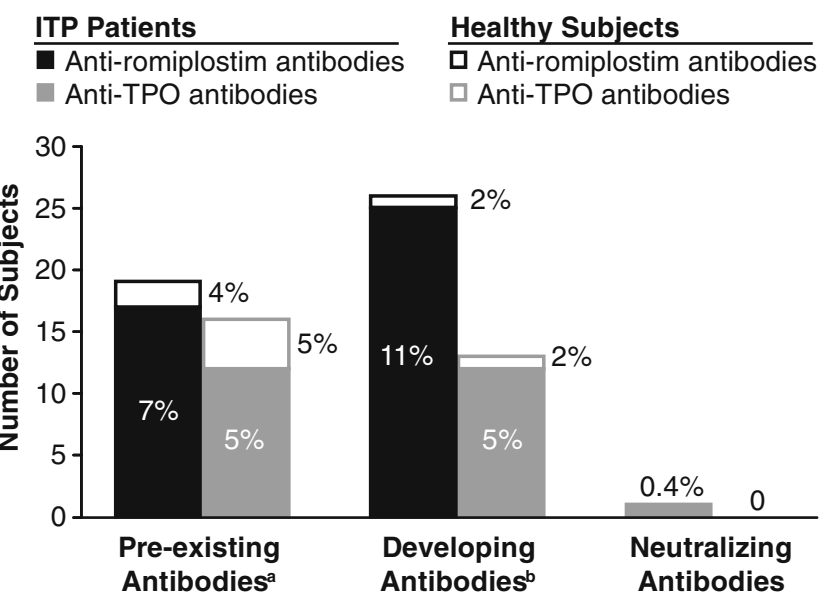

Fig. 2 Antibody incidence in ITP patients and healthy subjects across clinical studies. a Pre-existing antibodies to romiplostim or TPO include subjects who had binding antibodies prior to administration of romiplostim. Some of these antibodies continued to persist even after romiplostim dosing and were considered pre-existing. $b$ Post-exposure antibodies to romiplostim or TPO included subjects who had binding antibodies following dosing with romiplostim. Serum samples from healthy subjects that were a part of two initial Phase 1 studies were

kinetics of development of an immune response [21]. This information could help to provide guidance to predict the safety of these proteins during the clinical drug development process and help make informed treatment decisions. A sensitive SPR-based Biacore assay that was capable of detecting both low and high affinity antibodies was used to accomplish this approach.

Impact of binding and neutralizing antibodies on platelet counts

The ability to maintain the platelet counts at $50 \times 10^{9} / \mathrm{L}$ or above was used as a pharmacodynamic marker in two Phase III clinical trials to establish the efficacy of romiplostim [1719]. Subjects that were positive for "pre-existing" or "postexposure" antibodies did not have an apparent effect on the established platelet levels. One subject developed neutralizing antibody response against romiplostim. This subject presented with a trend of lower platelet counts that coincided with the development and maturation of the binding antibody response from week 36 to week 79 . The reduced platelet count of $37 \times 10^{9} / \mathrm{L}$ at week $79 /$ EOS could be attributed to the presence of binding and neutralizing antibodies to romiplostim. The platelet counts did not fall below baseline $\left(24 \times 10^{9} / \mathrm{L}\right)$ in this subject.

\section{Characterization of antibody response}

Antibodies to romiplostim and TPO were observed as early as week 9 post-dose for some subjects and these antibodies tended to persist for the duration of the study. Since the use evaluated for pre-existing and post-exposure binding antibodies to romiplostim and TPO. The antibody incidence was compared to that observed for ITP patients enrolled across ten clinical studies. ITP patients had a higher incidence of pre-existing and post-exposure antibodies to romiplostim as compared to the healthy subjects. Similarly, ITP patients had a higher post-exposure incidence of antiTPO binding antibodies compared to healthy subjects

of concurrent immunosuppressive rescue medication was markedly reduced in romiplostim-dosed subjects, immunogenicity assessment to romiplostim was not compromised. It was not possible to determine if the initial use of concurrent immunosuppressive medication could the development of an immune response to romiplostim due to low numbers of subject population who developed antibodies. Both low and high affinity antibodies were observed during the course of the clinical trials. The low affinity binding antibodies to romiplostim observed in the program did not impact the platelet profiles (data not shown). Higher affinity antibodies were observed with the maturation of the immune response; in one subject, such antibodies potentially had an impact on enhanced drug clearance. Epitope-mapping experiments indicated that among the subjects who demonstrated post-exposure antibodies to romiplostim, $70 \%$ were directed toward the TMP peptide, the active site of the molecule. Further experiments to characterize these antibodies showed that at least one subject had neutralizing antibodies to romiplostim and that these antibodies had been of the IgG1 isotype. These observations on the characteristics of a mature antibody response to romiplostim are consistent with our previous experience with erythropoiesis-stimulating agents, where high affinity, neutralizing antibodies directed towards the active site of the molecule, correlate with efficacy.

Cross-reactivity with TPO

As the target receptors for both romiplostim and TPO are the same in vivo, it was important to screen for antibodies cross- 


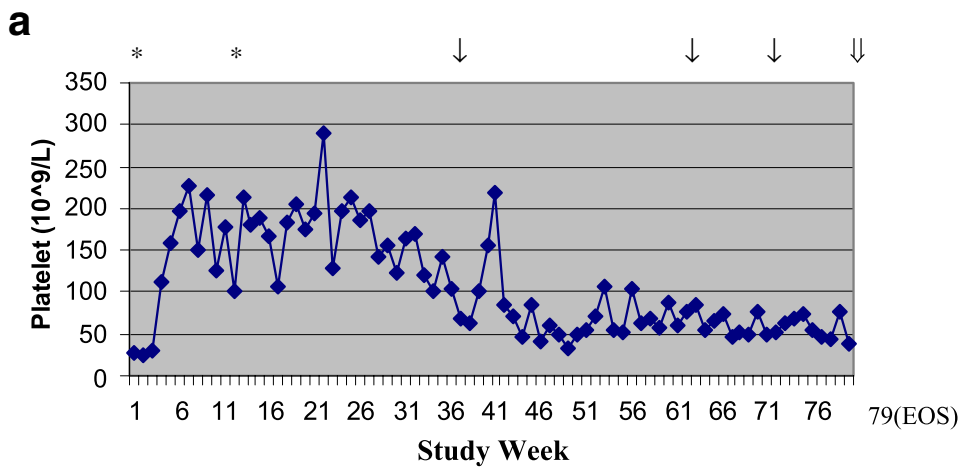

\begin{abstract}
$*=$ Negative for anti-romiplostim binding antibodies
$\downarrow=$ Positive for anti-romiplostim binding antibodies; negative for anti-romiplostim neutralizing antibodies

$\Downarrow=$ Positive for anti-romiplostim binding antibodies; positive for anti-romiplostim neutralizing antibodies
\end{abstract}

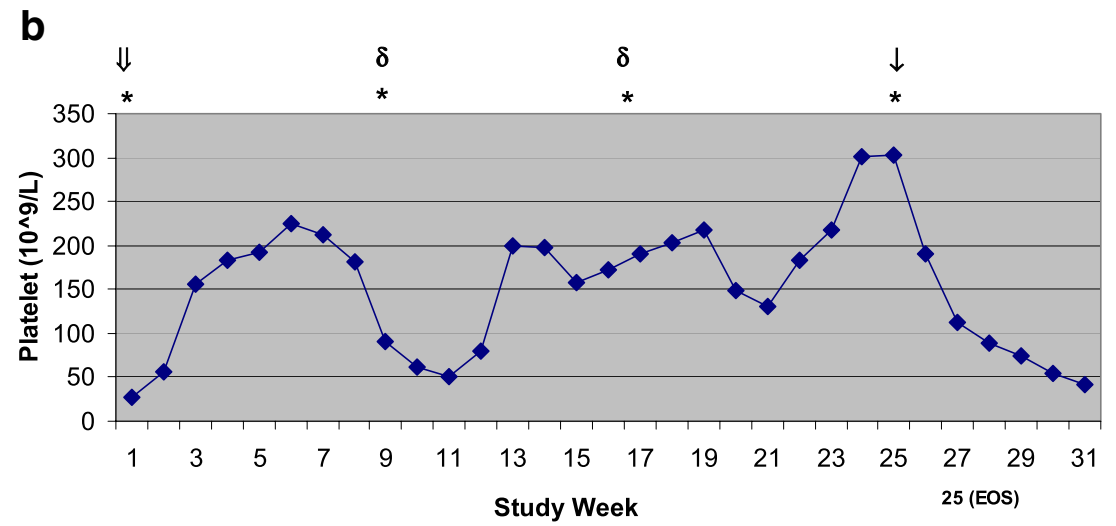

* = Negative for anti-romiplostim binding antibodies

$\downarrow=$ Positive for anti-TPO binding antibodies; negative for anti-TPO neutralizing antibodies

$\Downarrow=$ Positive for anti-TPO binding antibodies; positive for anti-TPO neutralizing antibodies

$\delta=$ Negative for anti-TPO binding antibodies; negative for anti-TPO neutralizing antibodies

Fig. 3 a Platelet profiles and antibody status of a subject from the roll-over extension study that developed neutralizing antibodies to romiplostim are provided. Blood samples obtained at week 1 and week 12 were negative for binding antibodies to romiplostim. At week 36 , week 60 , and at week 66 , blood samples were positive for anti-AMG 531 binding antibodies and negative for anti-AMG 531 neutralizing antibodies, and yielded negative results. The subject discontinued study at week 79 and the blood sample obtained at week 79/end of study (EOS) was positive for anti-AMG 531 binding antibodies and neutralizing antibodies. Single asterisks indicate negative for anti-romiplostim binding antibodies. Down arrows indicate positive for anti-romiplostim binding antibodies; negative for anti-romiplostim neutralizing antibodies. Double down arrows indicate positive for anti-romiplostim binding antibodies; positive for anti-romiplostim neutralizing antibodies. b Platelet profiles and antibody status of a subject from the roll-over extension study that

reactive with TPO. In previous clinical studies, administration of multiple doses of another thrombopoietic agent, pegylated recombinant human MGDF (PEG-rHuMGDF) to healthy volunteers and cancer subjects resulted in development of neutralizing antibodies to PEG-rHuMGDF that cross-reacted with TPO. Some of these subjects progressed to develop drug- had pre-existing antibodies to TPO. Blood samples obtained at week 1, week 9, week 17 , and week 25 were assessed for antibodies to romiplostim and TPO. Samples were negative for binding antibodies to romiplostim at all time-points tested. The sample collected at predose time-point prior to exposure to romiplostim was positive for both binding antibodies to TPO. Following dosing with romiplostim, samples obtained at week 9 and week 17 were negative for antibodies to TPO and positive for binding antibodies to TPO at week 25 . No obvious impact on platelets could be observed due to presence of these pre-exposure neutralizing antibodies to TPO. Single asterisks indicate negative for anti-romiplostim binding antibodies. Down arrows indicate positive for anti-TPO binding antibodies; negative for anti-TPO neutralizing antibodies. Double down arrows indicate positive for anti-TPO binding antibodies; positive for anti-TPO neutralizing antibodies. Delta indicates negative for anti-TPO binding antibodies; negative for anti-TPO neutralizing antibodies

induced autoimmune thrombocytopenia [6-8]. Romiplostim has been designed such that it can bind to and signal through the $\mathrm{cMpl}$ receptor, but has no amino acid sequence homology to TPO [22]. Thus, the risk to subject's development of neutralizing antibodies against romiplostim was limited to a loss of efficacy of the therapeutic protein. Our results support 
this concept in that none of the subjects administered romiplostim developed anti-TPO neutralizing antibodies.

Association of autoimmune disease state to the pre-existing and post-dose antibody development

The incidences of pre-existing and post-dose developing antibodies to romiplostim and TPO were compared across the placebo-dosed and romiplostim-dosed ITP and healthy subjects. Pre-existing antibodies were evaluated in baseline samples obtained from subjects prior to dosing. In the clinical ITP program, the frequency of pre-existing antibodies to romiplostim was $7 \%$ and to TPO was $5 \%$ in romiplostim-dosed subjects (Table 2). A similar high incidence of pre-existing antibodies was noted for the placebo-dosed group of ITP subjects $(9 \%$ for romiplostim and $13 \%$ for TPO; Table 3 ). In contrast, the incidence of pre-existing antibodies to romiplostim and TPO was $4 \%$ and $2 \%$, respectively, in the healthy subjects (Fig. 2).

This high incidence of pre-existing binding antibodies in subjects with ITP could be attributed to the sensitive Biacore screening assay that is capable of detecting low affinity binding antibodies. In addition the autoimmune disease state associated with ITP, could also contribute to the higher incidence of pre-existing anti-romiplostim antibodies in ITP subjects compared to healthy subjects. The ITP subjects also presented a trend of higher immunogenicity to romiplostim post-exposure to the drug ( $11 \%$ in ITP subjects compared to $2 \%$ in healthy subjects). Similarly, the incidence of anti-TPO binding antibodies was higher in ITP subjects $(5 \%)$ compared to healthy subjects $(2 \%)$ postexposure to romiplostim. This observation suggests that the autoimmune nature of ITP could be contributing to the predisposition to elicit higher immunogenicity. In this respect, pre-existing reactivity to TPO has been observed in subjects with autoimmune conditions like ITP [23, 24]. It is conceivable that molecular mimicry could account for detection of these pre-existing antibodies $[25,26]$.

In conclusion, an immunogenicity assessment was performed on all subjects treated with romiplostim during the clinical development program in ITP, using sensitive assays to detect binding and neutralizing antibodies. Although binding antibodies were observed against romiplostim and TPO in multiple subjects post-exposure to romiplostim, only one subject was found positive for the presence of antibodies capable of neutralizing romiplostim which may account for the reduced platelet levels. The subject was eventually negative for neutralizing antibody response at the time of follow-up after discontinuation of romiplostim. None of the subjects in the study were positive for antibodies capable of neutralizing TPO. The limitation of this immunogenicity data is the relatively low number of subjects evaluated in this orphan indication. When evaluated in a larger cohort of subjects, the incidence of romiplostim immunogenicity may be influenced by supportive therapies, severity of disease states, and genetic factors. A postmarketing surveillance program is in place to monitor subjects for binding and neutralizing antibodies to address the risks and limitations of the study described here.

Acknowledgments The authors would like to thank the following individuals who have contributed significantly during the clinical development of romiplostim over the years: Daniel Mytych, Eugene Koren, Roger Craveiro, Erica Bramhall, and Janet Nichol. The authors would also like to acknowledge the support of Michelle Zakson in the finalization of the manuscript.

Open Access This article is distributed under the terms of the Creative Commons Attribution Noncommercial License which permits any noncommercial use, distribution, and reproduction in any medium, provided the original author(s) and source are credited.

\section{References}

1. Bussel J, Kuter D, George J (2006) Romiplostim, a thrombopoiesisstimulating protein, for chronic ITP. N Engl J Med 355:1672-1681

2. Kuter D (2007) New thrombopoietic growth factors. Blood 109:4607-4616

3. Bottiger L, Westerholm B (1972) Thrombocytopenia. Incidence and aetiology. Acta Med Scand 191:535-540

4. Kelton J, Gibbons S (1982) Autoimmune platelet destruction: idiopathic thrombocytopenic purpura. Semin Thromb Hemost 8:83-104

5. McMillan R (1981) Chronic idiopathic thrombocytopenic purpura. N Engl J Med 304:1135-1147

6. Li J, Yang C, Yea X (2001) Thrombocytopenia caused by the development of antibodies to thrombopoietin. Blood 98:3241-3248

7. Crawford J, Glaspy J, Belani C (1998) A randomized, placebocontrolled, blinded, dose-scheduling trial of pegylated recombinant human megakaryocyte growth and development factor (PEG-rHuMGDF) with Filgrastim support in non-small cell lung cancer (NSCLC) patients treated with paclitaxel and carboplatin during multiple cycles of chemotherapy [abstract]. Proc Am Soc Clin Oncol 17:285

8. Basser R, O'Flaherty E, Green M, Edmonds M, Nichols J (2002) Development of pancytopenia with neutralizing antibodies to thrombopoietin after multicycle chemotherapy supported by megakaryocyte growth and development factor. Blood 99:2599-2602

9. Shankar G, Devanarayan V, Amaravadi L (2008) Recommendations for the validation of immunoassays used for detection of host antibodies against biotechnology products. J Pharm Biomed Anal 48:1267-1281

10. Gupta S, Indelicato S, Jethwa V (2007) Recommendations for the design, optimization, and qualification of cell-based assays used for the detection of neutralizing antibody responses elicited to biological therapeutics. J Immunol Methods 32:1-18

11. Koren E, Smith H, Shores E (2008) Recommendations on riskbased strategies for detection and characterization of antibodies against biotechnology product. J Immunol Methods 333:1-9

12. Swanson S, Ferbas J, Mayeux P (2004) Evaluation of methods to detect and characterize antibodies against recombinant human erythropoietin. Nephron Clin Pract 96:88-95

13. Lofgren J, Dhandapani S, Pennucci J (2007) Comparing ELISA and surface plasmon resonance for assessing clinical immunogenicity of panitumumab. J Immunol 178:7467-7472

14. Mytych D, La S, Barger T, Ferbas J, Swanson S (2009) The development and validation of a sensitive, dual-flow cell, SPR- 
based biosensor immunoassay for the detection, semi-quantitation, and characterization of antibodies to darbepoetin alfa and epoetin alfa in human serum. J Pharm Biomed Anal 49:415-426

15. Safsten $P$ (2009) Epitope mapping by surface plasmon resonance. Methods Mol Biol 524:67-76

16. Sharon XM, Min X, Gary E (1995) Megakaryocyte growth and development factor and interleukin-3 induce patterns of proteintyrosine phosphorylation that correlate with dominant differentiation over proliferation of mpl-transfected 32D cells. Blood $86: 4532-4543$

17. Kuter D, Bussell J, Lyons R (2008) Efficacy of romiplostim in patients with chronic immune thrombocytopenic purpura: a double- blind randomized controlled trial. Lancet 371:395-403

18. Bussel J, Kuter D, Pullarkat V (2009) Safety and efficacy of longterm treatment with romiplostim in thrombocytopenic patients with chronic ITP. Blood 113:2161-2171

19. Shirasugi Y, Ando K, Hashino S (2009) A phase II, open-label, sequential-cohort, dose-escalation study of romiplostim in Japanese patients with chronic immune thrombocytopenic purpura. Int J Hematol 90:157-165
20. George J, Mathias S, RS G (2009) Improved quality of life for romiplostim-treated patients with chronic immune thrombocytopenic purpura: results from two randomized, placebo-controlled trials. Br J Haematol 144:409-415

21. Swanson S (2006) Immunogenicity issues in drug development. J Immunotoxicol 3:165-172

22. Broudy V, Lin N (2004) AMG 531 stimulates megakaryopoiesis in vitro by binding to Mpl. Cytokine 25:52-60

23. Aledort L, Hayward C, Chen M, Nichol J, Bussel J (2004) Prospective screening of 205 patients with ITP, including diagnosis, serological markers, and the relationship between platelet counts, endogenous thrombopoietin, and circulating antithrombopoietin antibodies. Am J Hematol 76:205-213

24. Fureder W, Firbas U (2002) Serum thrombopoietin levels and anti-thrombopoietin antibodies in systemic lupus erythematosus. Lupus 11:221-226

25. Oldstone M (1998) Molecular mimicry and immune-mediated diseases. Faseb J 12:1255-1265

26. Albert L, Inman R (1999) Molecular mimicry and autoimmunity. N Engl J Med 34:2068-2074 